\section{Measuring animal well-being}

SIR - In his Commentary "Today's non-Orwellian animal farm"l, Jukes claims that the productivity of farm animals is an index of their weli-being and that, because economic success for intensive agriculture is measured by productivity, the well-being of the animals involved is protected.

It is true that a sudden fall in productivity may indicate a welfare problem, but welfare cannot simply be measured by productivity. The definition and measurement of animal welfare have been studied and described extensively and several comprehensive reviews are available ${ }^{2-4}$

One problem with using productivity to measure welfare is that the welfare of an animal is a property of an individual, but productivity, particularly in intensive agriculture, is usually measured in terms of flock or herd production. Another problem is that one measurement may

\section{Hadley protests}

SIR - A recent story by Christopher Anderson concerning my dealings with Congressman John Dingell's oversight and investigations subcommittee of the US House of Representatives Committee on Energy and Commerce quoted a statement by the National Institutes of Health (NIH) concerning this matter (Nature 355, 98; 1992).

The NIH statement insinuates that I have conducted myself improperly with respect to the subcommittee. This is patent nonsense. Moreover, contrary to the NIH statement, I have not "recently been reminded" about any NIH policy with respect to responding to congressional requests for information, nor is there any reason I should have been so reminded. NIH acknowledge their awareness that I was to be interviewed by subcommittee staff during the meeting reported in the Nature story, yet the NIH statement gratuitiously asserts that it is NIH policy that employees must not "reveal or discuss without authorization confidential information obtained in the course of their current or previous duties." NIH do not suggest that their putative policy applies to requests for information from duly authorized investigative subcommittees of the United States Congress. The spurious raising of the "confidentiality" issue in this context is a red herring, an apparent response by the NIH administration to its demonstrated inadequacies, as indicated by Anderson's story. give different results for animals of different individual value. For example, a mortality rate of 7 per cent is not unusual in rearing veal calves to six months of age and appears to be acceptable to many farmers. The same mortality rate would not be economically acceptable to a farmer rearing valuable dairy replacement calves.

The major problem, however, is to decide which measurement of productivity to use. To quote from a review of this problem in respect of poultry", "a change in an environment variable may reduce the number of eggs produced, but increase egg weight, leaving egg mass output the same. Depending on the measure of productivity selected, the change could be said to be an extreme example, but in the course of investigating the welfare of several species of farm animal over the past few years, I have found that producers do indeed use such arguments.

For example, laying hens kept in battery cages often have poor feather cover and poor skin condition but high rates of egg production. Foxes kept in cages usually have good fur and skin condition but often have low reproductive rates. I have been earnestly informed by battery cage producers that egg production is the only real measure of a hen's welfare and that skin and feather condition are irrelevant, whereas fox farmers tell me that reproductive rates have little or nothing to do with welfare but a good shiny coat is a true indication of a happy fox (presumably as long as the fox is still wearing it).

I am more than a little surprised to find a professor of biology giving credence to this folklore, even if, as he says, he worked on a farm in the 1920 s.

\section{Avenue du Mistral,}

ANDREW J. WILSON

\section{Brussels,}

Belgium

\section{Jukes, T. H. Nature 355, 582 (1992)}

2. Broom, D. M. Appl Anim. Behav Sci. 20,5 (1988)

3. Fraser, A. F. \& Broom, D. M. Farm Animal Behaviour and Welfare (Saunders. New York, 1990)

4. Broom, D. M. J. Anim. Sci. 69, 4167-4175 (1991).

5. Hill, J. A. World's Poult. Sci. J. 39, 24-31 (1983)

SIR - Jukes questions the notion that animals feel better when they have more space for roaming (his argument: "how do we know this is true?"). He should ask himself why chicken get their beaks cut and pigs their canine tooth removed - not because the animals smile too much but because they attack each other under their crowded stress situation. Why did Jukes compare the situation of these animals jammed in cages with crowded human gatherings such as watching sports where the participants come for a short time and leave as they please? Why not, with respect to the impossibility of escaping and imminent death, compare it to Hitler's concentration camps? Jukes argues further that heavy drug use in farm animals is necessary because the prevention of disease also prevents suffering. He should have mentioned that those animals are much more prone to diseases because of the conditions in which they are raised.

University of California

AXEL SCHÖNTHAL

San Diego Cancer Center, La Jolla, California 92093-0636, USA

SIR - I agree with Jukes that it is unfair to allege that people engaged in farming are oblivious to animal welfare, but it is certainly not unfair to question the impact of modern farm systems on farm animal well-being nor even to allege that such systems are inhumane. The "fairness" of the allegation depends on the definition of inhumane and the quality of the supporting data and argument. In fact, there is a wealth of data indicating that close confinement compromises the well-being of poultry, pigs and other farm animals. The questions now focus on the extent to which well-being is compromised, and the potential to develop appropriate confinement systems that retain most of the advantages for the farmers and the animals while eliminating most of the adverse effects.

Tufts University,

ANDREW N. ROWAN

Center for Animals and Public Policy,

200 Westboro Road, North Grafton,

Massachusetts 01536, USA

\section{Promotion in Italy}

SIR - I was very surprised to see that Baccarini et al. (Nature 356, 188; 1992) write that "as regards clinical teaching in haematology, the activity.. . . needs to be evaluated also in terms of clinical and professional ability...." The Italian law states in Article 41, law 380, that "promotion to full professor is by national public competitions in order to establish the scientific maturity of the candidates". As there are no written or oral examinations and no practical tests, how can their professional clinical capacity be evaluated?

The only element remaining of this law is the scientific activity of the candidates represented by their publications. If these are clinical papers they should obviously be evaluated as applicants for a clinical competition.

Universita degli Studi

FERNANDO AIUTI

di Roma 'La Sapienza',

Policlinico Umberto 1.

o0161 Rome,

Italy 